\title{
POSTEROSUPERIOR SURGICAL ACCESS ROUTE FOR TREATMENT OF ACROMIOCLAVICULAR DISLOCATIONS: RESULTS FROM 84 SURGICAL CASES
}

Danilo Canesin Dal Molin', Fabiano Rebouças Ribeiro², Rômulo Brasil Filho², Cantídio Salvador Filardi Junior ${ }^{3}$, Antonio Carlos Tenor Junior ${ }^{2}$, Willian Nandi Stipp', Rodrigo Souto Borges Petros ${ }^{1}$

\section{ABSTRACT}

Objective: To evaluate the results from surgical treatment of 84 cases of acute acromioclavicular dislocation, using a posterosuperior access route. Methods: Eighty-four cases of acute acromioclavicular dislocation (grade III in the Allman-Tossy classification) operated between November 2002 and May 2010 were evaluated. The patients' mean age was 34 years. The diagnoses were made using clinical and radiographic evaluations. The patients were operated by the same surgical team, within three weeks of the date of the trauma, using a posterosuperior approach to the shoulder to access the top of the base of the coracoid process for placement of two anchors, which were used in reducing the dislocation. The minimum follow-up was 12 months. The postoperative clinical- radiographic evaluation was done using the modified Karlsson criteria and the University of California at Los Angeles (UCLA) score. Results: $92.8 \%$ of the 84 patients treated presented good or excellent results, and 7.2\% presented fair or poor results, using the UCLA assessment score. According to the modified Karlsson criteria, 76.2\% were assessed as grade A, 17.9\% as grade B and 5.9\% as grade $\mathrm{C}$. Conclusion: The posterosuperior access route to the shoulder is a new option for accessing the coracoid process and treating acromioclavicular dislocation, with clinical and radiographic results equivalent to those in the literature.

Keywords - Acromioclavicular Joint/anatomy \& histology; Acromioclavicular Joint/injuries; Acromioclavicular Joint/surgery

\section{INTRODUCTION}

Acromioclavicular dislocation is a common lesion in orthopedic practice ${ }^{(1)}$. The commonest trauma mechanism is a fall on the shoulder, with force applied directly on the acromion with the shoulder adducted $^{(2)}$. It occurs most commonly among young adults because it is associated with impact sports and high-speed vehicle accidents ${ }^{(3,4)}$.

The classification system of Tossy et $a l^{(5)}$ divides acromioclavicular dislocations into three types, among which types I and II (mild and moderate) should be treated conservatively and type III (severe, with dislocation greater than $1 \mathrm{~cm}$ or greater than the thickness of the clavicle) should be treated surgically. The classification system of Rockwood et al ${ }^{(6)}$ modified type III and added types IV, V and VI to Tossy's classification. The treatment for Rockwood's types I and II is initially non-surgical ${ }^{(2,7)}$. The treatment for type III remains a matter for discussion, since it depends on the patient's age, activities and deformities,

1 - Trainee Physician, specializing in Shoulder and Elbow Surgery at the Orthopedics and Traumatology Clinic, Public Servants' Hospital of the State of São Paulo (HSPE), São Paulo, SP, Brazil.

2 - Attending Physician in the Shoulder and Elbow Group, Orthopedics and Traumatology Clinic, Public Servants' Hospital of the State of São Paulo (HSPE), São Paulo, SP, Brazil (HSPE), São Paulo, SP, Brazil.

3 - Head of the Shoulder and Elbow Group, Orthopedics and Traumatology Clinic, Public Servants' Hospital of the State of São Paulo (HSPE), São Paulo, SP, Brazil.

Work performed in the "Paulo Francisco Morato de Oliveira" Public Servants' Hospital of the State of São Paulo (HSPE), São Paulo, SP.

Correspondence: Rua Borges Lagoa 1755, sala 180, $1^{\circ}$ andar, Vila Clementino, 04038-034 São Paulo, SP. Fax: (11) 5573-3087. E-mail: danilo.cdm@hotmail.com.br Work received for publication: November 7, 2011; accepted for publication: February 14, 2012.

The authors declare that there was no conflict of interest in conducting this work 
while types IV, V and VI require surgical treatment ${ }^{(8)}$.

More than 75 techniques have been described for surgically treating acromioclavicular dislocation, but none of them has been established as the gold standard ${ }^{(9)}$. The techniques include fixation of the acromioclavicular joint using wires or a plate ${ }^{(10,11)}$, transfer of the coracoacromial ligament ${ }^{(12)}$, fixation of the coracoacromial interval using a screw, suturing anchors or lashing with suturing wires ${ }^{(13,14)}$ and reconstruction of the coracoclavicular and acromioclavicular ligaments ${ }^{(15)}$.

The modifications to the techniques for fixing the clavicle to the coracoid process go from use of screws or subcoracoid lashings to use of anchors and material of Endobutton ${ }^{\circledR}$ type (flip-button ${ }^{\circledR}$ ), which can be used as open, minimally invasive or arthroscopic procedures $^{(16-18)}$. Anchors have the advantage that they can be placed more proximally to the anatomical insertion site of the coracoclavicular ligaments ${ }^{(19)}$.

The posterosuperior shoulder access route for treating acromioclavicular dislocations was presented at the $34^{\text {th }}$ Brazilian Congress of Orthopedics and Traumatology (2002) and was awarded the "Prof. Orlando Pinto de Souza" award for creativity. It was developed by the Shoulder and Elbow Group of the Public Servants' Hospital of the State of São Paulo (HSPE/IAMSPE) with the aims of enabling easy access to the top of the base of the coracoid process, maintaining a more anatomical reduction of the acromioclavicular joint and preserving the anterior portion of the deltoid muscle, thereby allowing better functional recovery for the shoulder.

The aim of the present study was to evaluate the clinical and radiographic results from patients who underwent treatment for acute acromioclavicular dislocation by means of a posterosuperior shoulder access route.

\section{METHODS}

Eighty-four cases of acute acromioclavicular dislocation (grade III of Tossy's classification) were treated surgically between November 2002 and May 2010 using the posterosuperior access route. The operations were performed by the Shoulder and Elbow Group of the Public Servants' Hospital of the State of São Paulo (HSPE/IAMSPE).

Over this period, 102 patients underwent surgery to treat acute acromioclavicular dislocations. Eighteen patients were excluded from this study because of Rev Bras Ortop. 2012;47(5):563-7 either loss from follow-up (12) or associated lesions in the same limb (six), which made the assessment methods impossible.

The diagnosis of acromioclavicular dislocation was made by means of physical and radiographic examinations on the patient. The patients included in the study presented less than 21 days of evolution from the trauma and had lesions of Tossy grade III.

The patients' ages ranged from 17 to 61 years, with a mean of 33.9 years. Among the 84 patients evaluated, $68(80.9 \%)$ were male and $16(19.1 \%)$ were female. The dominant side was affected in 53 patients $(63 \%)$ and the non-dominant side in 31 patients (37\%). The mean length of follow-up was 54 months, with a minimum of 12 months and maximum of eight years and five months.

The patients were assessed using the modified criteria of Karlsson et al ${ }^{(20)}$ (Chart 1) and according to the score of the University of California in Los Angeles (UCLA) ${ }^{(21)}$. Radiographic examinations were performed using the bilateral anteroposterior view on the acromioclavicular joint, anteroposterior view on the chest and axillary view on the shoulder, bilaterally.

Chart 1 - Modified Karlsson criteria for clinical-radiographic evaluation of acromioclavicular dislocations.

Grade A: without pain, normal movements and without muscle atrophy; anatomical restoration of the joint or displacement less than $5 \mathrm{~mm}$ on radiography.

Grade B: slight pain, slight limitation of movements and slight muscle atrophy; with displacement greater than $5 \mathrm{~mm}$ on radiography.

Grade C: with pain, with muscle atrophy and with significant limitation of movements; with displacement greater than $5 \mathrm{~mm}$ on radiography.

\section{SURGICAL TECHNIQUE}

After administration of general anesthesia and regional blockade, the patient was positioned semi-seated on the surgical table. Asepsis was performed on the affected shoulder and respective limb, while leaving the latter free for movement. A sabre incision was made in the skin and subcutaneous tissue in the anteroposterior direction, starting $1 \mathrm{~cm}$ anteriorly to the acromioclavicular joint and going to $3 \mathrm{~cm}$ posteriorly.

The trapezoid muscle was deinserted from the clavicle and was pushed away posteriorly in order to view the top of the base of the coracoid process (Figure 1). Two 5mm screwed titanium anchors with 

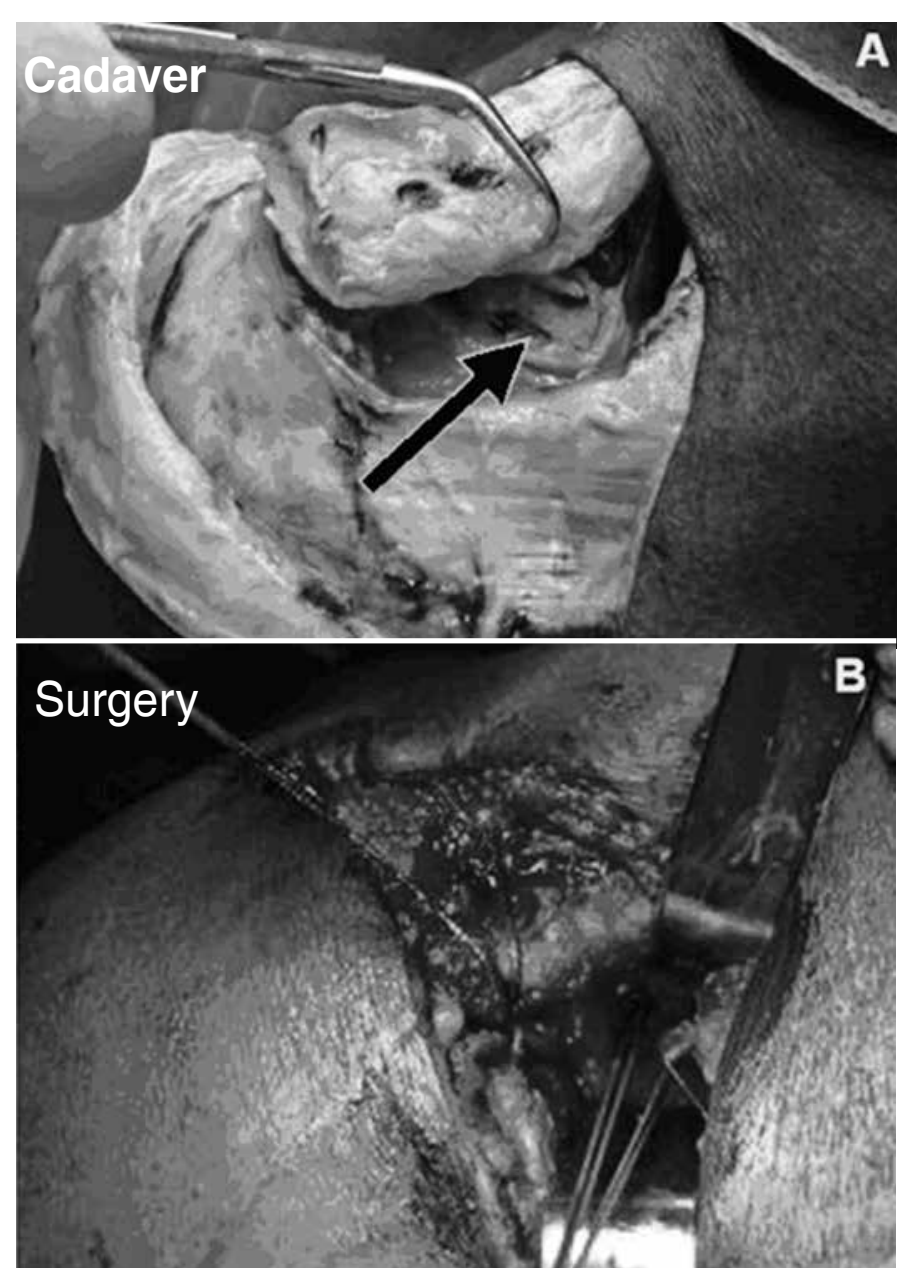

Figure 1 - (A) Deinsertion of the trapezium muscle from the distal clavicle, which was subsequently pushed away so that the top of the base of the coracoid process (arrow) could be viewed, in a cadaver. (B) Anchors positioned in the coracoid process during the surgery.

high-resistance threads were then fixed to the top of the base of the coracoid process. In the clavicle, two holes were made in the superoinferior direction, at the level of the conoid tubercle and roughly along the line of the clavicle. The lateral orifice was used as the entry point, from inferiorly to superiorly, for the threads from the anchor that was fixed most laterally in the coracoid process. The threads from the anchor that was fixed most medially in the coracoid process were passed through the medial orifice of the clavicle. To pass the anchor threads through the orifices that were made in the clavicle, a doubled-over fine steel wire was used. The acromioclavicular joint was then reduced and the threads were tied off above the clavicle (Figure 2). The trapezoid muscle was reinserted into the clavicle and deltoid-trapezoidal fascia. Control radiographs were produced after the operation (Figure 3).

During the postoperative evolution, the patient used
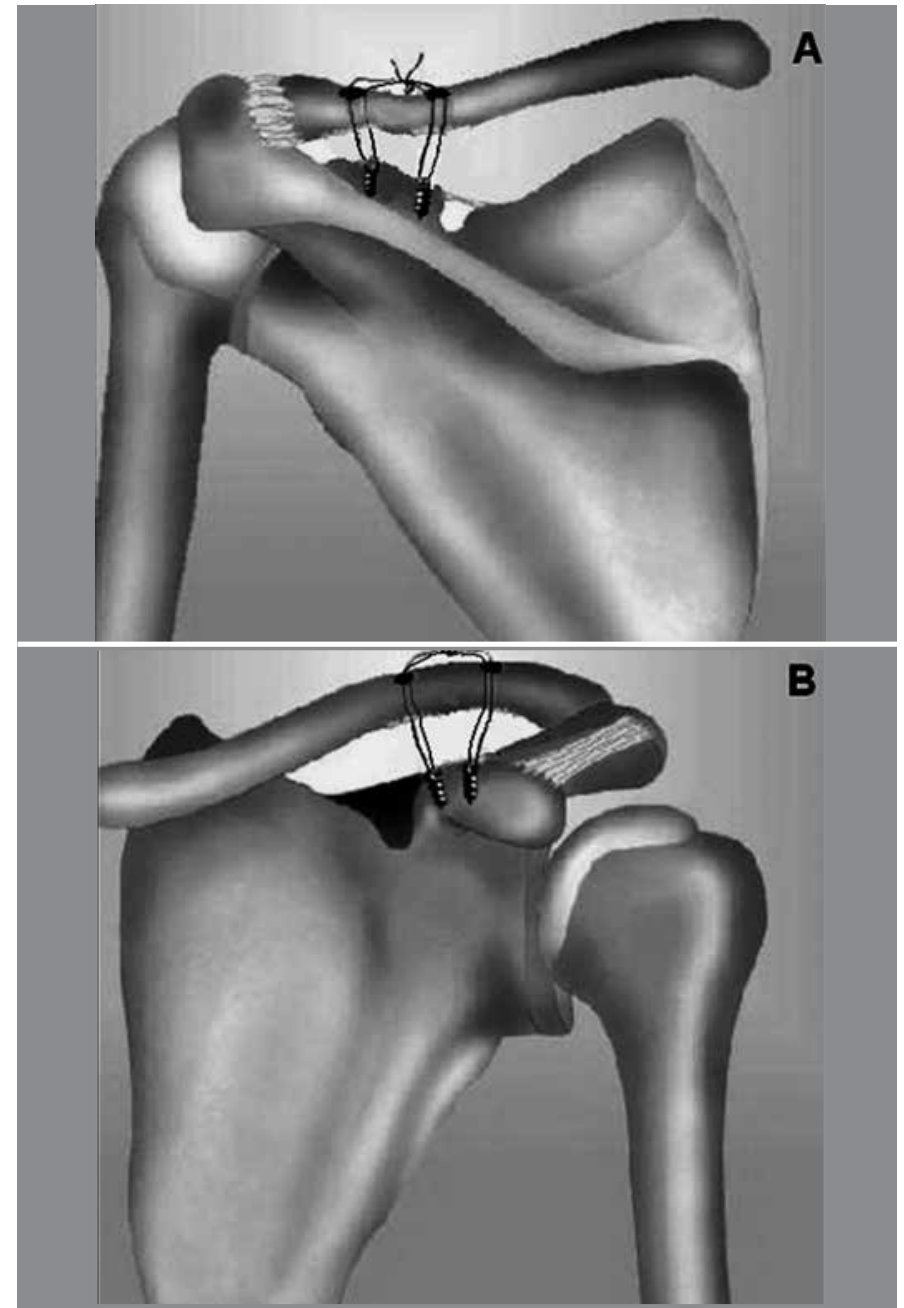

Figure 2 - Schematic diagram showing the positioning of the anchors and the holes made in the clavicle: $(A)$ posterior view; and (B) anterior view.

a Velpeau sling for 40 days and was instructed to perform active flexion of the elbow starting in the immediate postoperative period. Pendulum exercises were performed starting in the third week after the operation.

\section{RESULTS}

Out of the 84 cases evaluated, $52(61.9 \%)$ were considered to have excellent results according to the UCLA score, $26(30.9 \%)$ had good results and six $(7.2 \%)$ had fair results. None of the patients presented poor results. Among the 26 patients with good results, 18 had a score of 33 , thus losing two points regarding the pain criterion (Figure 4).

Thirteen patients $(15.4 \%)$ presented loss of reduction during the postoperative period. In three cases (3.5\%), the loss occurred within the first six weeks after the operation. All the patients who presented fair results according to the UCLA score showed losses of joint 


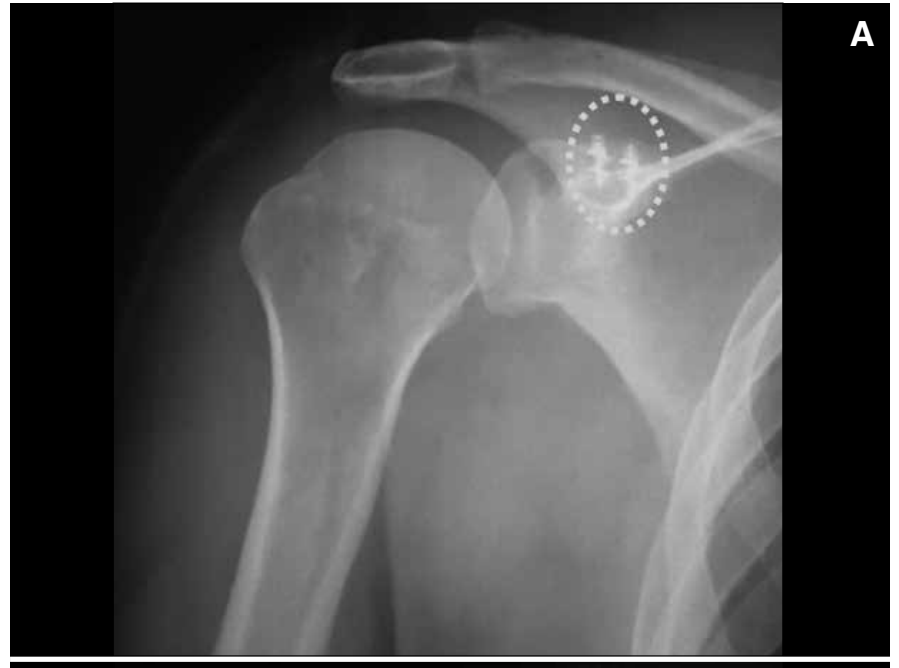

B

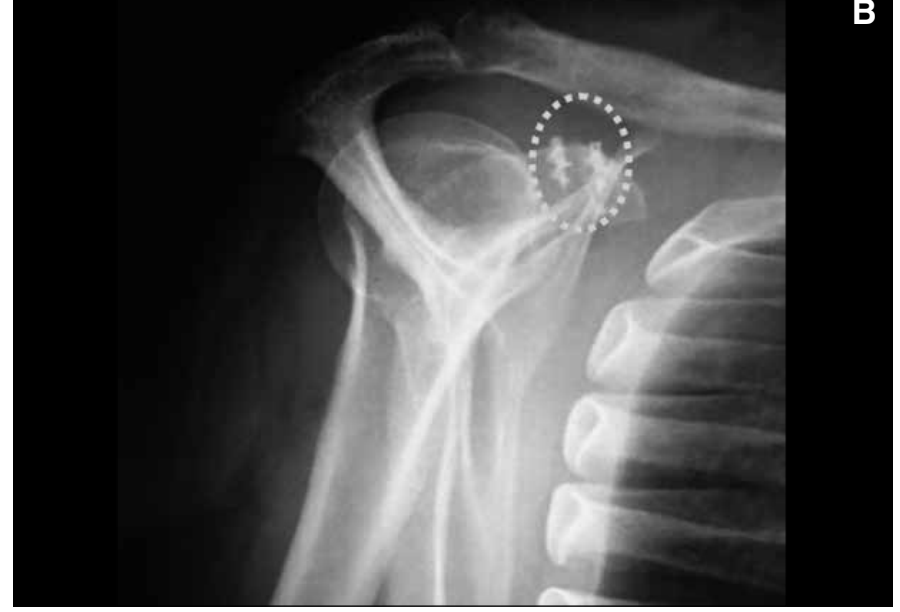

Figure 3 - Postoperative radiograph of the shoulder in anteroposterior view (A) and lateral view $(B)$, demonstrating the anchors in the coracoid process and the reduction of the acromioclavicular joint.

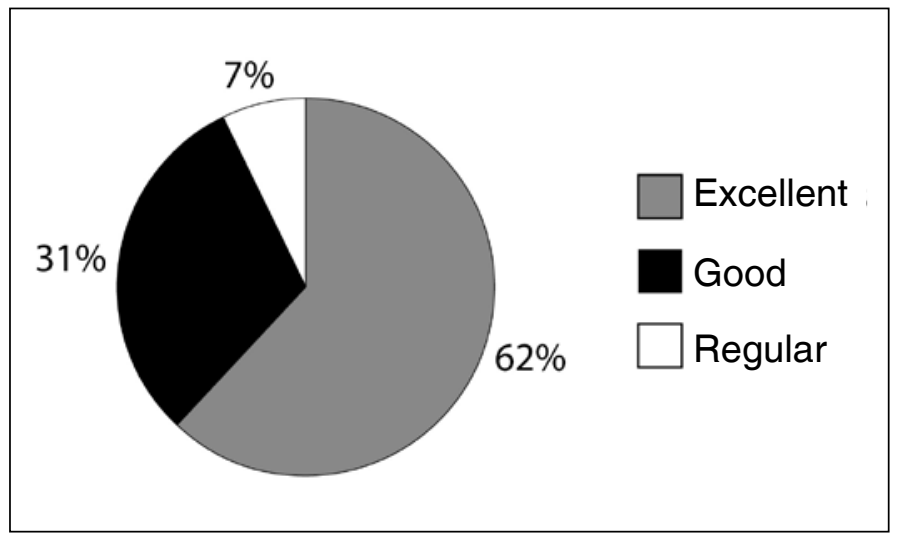

Figure 4 - UCLA score results for the 84 patients operated through the posterosuperior access route to treat acromioclavicular dislocations.

reduction, but they did not present functional limitation and there was no need for any new intervention.

According to the modified Karlsson criteria, 64 patients $(76.2 \%)$ presented grade A, $15(17.9 \%)$ grade $\mathrm{B}$ and five $(5.9 \%)$ grade $\mathrm{C}$ (Figure 5 ).

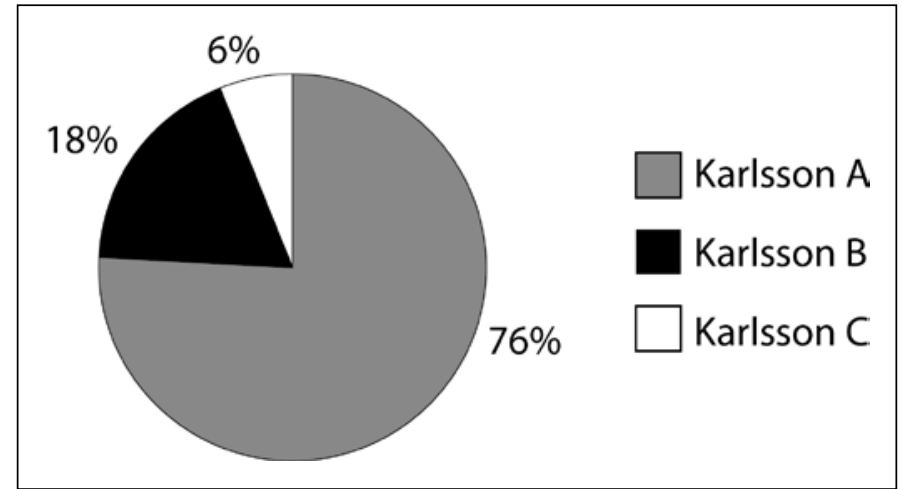

Figure $\mathbf{5}$ - Modified Karlsson score results for the 84 patients operated by means of the posterosuperior access route to treat acromioclavicular dislocations.

\section{DISCUSSION}

The aim in surgically treating acute acromioclavicular dislocations is to achieve anatomical reduction so as to enable healing of the soft tissues and recovery of the previous functioning of the joint. The large number of procedures described in the literature demonstrates the lack of consensus regarding the ideal method ${ }^{(16)}$.

The techniques for reconstructing the coracoclavicular ligaments through transferring the coracoacromial ligament or using biological or synthetic grafts present the complication of loss of reduction. This has been found in up to $24 \%$ of the cases treated using the Weaver-Dunn method ${ }^{(15,22)}$. The lower resistance of the coracoacromial ligament and the change in direction of the force vector in relation to the coracoclavicular ligaments are the main causes of this complication ${ }^{(23)}$.

Despite the advantage of technical simplicity, acromioclavicular fixation by means of metal wires may present the complications of migration of the wires, infection, arthrosis and loss of reduction ${ }^{(24,25)}$.

There are several techniques for fixation of the clavicle to the coracoid process ${ }^{(9)}$. Bosworth screws present the disadvantage of requiring a new procedure to remove them, and they present high rates of osteolysis in the clavicle ${ }^{(9)}$. High-resistance threads that are tied off in the subcoracoid area may cause local bone erosion and maintain the anterior subluxation of the clavicle, and this has been shown to cause pain, arthritis and diminished strength ${ }^{(26)}$. Fixation of the clavicle to the coracoid process using suture anchors facilitates the operative technique, although the anterior access route still requires dissection of the anterior portion of the deltoid muscle and maintains residual subluxation of the clavicle, since it does not reestablish the force 
vector of the coracoclavicular ligaments.

The posterosuperior shoulder access route provides direct access to the top of the base of the coracoid process without damage to the anterior deltoid muscle. This may keep the joint reduction more anatomical and reestablish joint stability because of the positioning of the anchors in the anatomical position of the ruptured coracoclavicular ligaments.

The results obtained were analyzed using the UCLA scale because this is the method most often used in the literature for analyzing the results from surgical treatment of acromioclavicular dislocations. The Karlsson criteria were used because they are specific for diseases that involve the acromioclavicular joint, but they were modified so that the functional limitations and loss of reduction would be better quantified in the evaluation.

Algarín et $a l^{(27)}$ evaluated 42 patients who were treated using a minimally invasive technique for coracoclavicular fixation using a cortical screw and acromioclavicular fixation using Kirschner wires. They found that $57 \%$ of their results were excellent and

\section{REFERENCES}

1. Bannister GC, Wallace WA, Stableforth PG, Hutson MA. The management of acute acromioclavicular dislocation. A randomised prospective controlled trial. J Bone Joint Surg Br. 1989;71(5):848-50.

2. Lemos MJ. The evaluation and treatment of the injured cromioclavicular joint in athletes. Am J Sports Med. 1998;26(1):137-44.

3. Bishop JY, Kaeding C. Treatment of the acute traumatic acromioclavicular separation. Sports Med Arthrosc. 2006;14(4):237-45.

4. Mazzocca AD, Arciero RA, Bicos J. Evaluation and treatment of acromioclavicular joint injuries. Am J Sports Med. 2007;35(2):316-29.

5. Tossy JD, Mead NC, Sigmond HM. Acromioclavicular separations: useful and practical classification for treatment. Clin Orthop Relat Res. 1963;28:111-9.

6. Rockwood CA Jr, Williams GR Jr, Young DC. Disorders of the acromioclavicular joint. Rockwood CA Jr, Matsen FA 3rd, editors. The shoulder. Philadelphia: Saunders: 1998. p. 485-553.

7. Mouhsine E, Garofalo R, Crevoisier X, Farron A. Grade I and II acromioclavicular dislocations: results of conservative treatment. J Shoulder Elbow Surg. 2003;12(6):599-602.

8. Nissen CW, Chatterjee A. Type III acromioclavicular separation: results of a recent survey on its management. Am J Orthop (Belle Mead NJ). 2007;36(2):89-93.

9. Johansen JA, Grutter PW, McFarland EG, Petersen SA. Acromioclavicular joint injuries: indications for treatment and treatment options. J Shoulder Elbow Surg.2011;20(Suppl 2):S70-82.

10. Phemister PB. The treatment of dislocation of the acromioclavicular joint by open reduction and threaded wire fixation. J Bone Joint Surg 1942; 24:166-68.

11. Sim E, Schwarz N, Höcker K, Berzlanovich A. Repair of complete acromioclavicular separations using the acromioclavicular-hook plate. Clin Orthop Relat Res. 1995;(314):134-42.

12. Weaver JK, Dunn HK. Treatment of acromioclavicular injuries, especially complete acromioclavicular separation. J Bone Joint Surg Am. 1972;54(6):1187-94.

13. Bosworth BM. Acromioclavicular separation: new method of repair. Surg Gynecol Obstet. 1941;73:866-71.

14. Breslow MJ, Jazrawi LM, Bernstein AD, Kummer FJ, Rokito AS. Treatment of acromioclavicular joint separation: suture or suture anchors? J Shoulder Elbow Surg. 2002;11(3):225-9.

15. Carofino BC, Mazzocca AD. The anatomic coracoclavicular ligament reconstruction: surgical technique and indications. J Shoulder Elbow Surg. 2010;19(Suppl 2):37-46.
$29 \%$ were good, using the UCLA score, and their values were close to what we obtained in our study.

Lädermann et al ${ }^{(28)}$ conducted a clinical, radiographic and isokinetic evaluation on 37 patients who underwent coracoclavicular cerclage and acromioclavicular stabilization using non-absorbable sutures, to treat acromioclavicular dislocations. Seven patients (18.9\%) presented loss of reduction, and this was correlated with less satisfactory results, just like in our study.

The posterosuperior shoulder access route for placement of suture anchors at the base of the coracoid process was shown to be easy to learn and reproducible, and the results presented were similar to those from techniques described in the literature, with a low rate of postoperative complications.

\section{CONCLUSION}

The posterosuperior shoulder access route is a new option for accessing the coracoid process and treating acromioclavicular dislocations, with clinical and radiographic results equivalent to those in the literature.

16. Simoni M, Brandão BL, Tumolo LH. Tratamento da luxação acromioclavicular com amarrilhos coracoclaviculares por meio de duas miniincisões. Rev Bras Ortop. 2005;40(8):483-9.

17. DeBerardino TM, Pensak MJ, Ferreira J, Mazzocca AD. Arthroscopic stabilization of acromioclavicular joint dislocation using the AC graftrope system. J Shoulder Elbow Surg. 2010;19(Suppl 2):47-52.

18. Vieira LAG, Visco A, Fernandes LFD, Cordero NGG. Tratamento artroscópico da luxação acromio-clavicular pelo método "Tight Rope" (Arthrex®). Rev Bras Ortop. 2009;44(1):52-6.

19. Wellmann M, Zantop T, Weimann A, Raschke MJ, Petersen W. Biomechanical evaluation of minimally invasive repairs for complete cromioclavicular joint dislocation. Am J Sports Med. 2007;35(6):955-61.

20. Karlsson J, Arnarson H, Sigurjónsson K. Acromioclavicular dislocations treated by coracoacromial ligament transfer. Arch Orthop Trauma Surg. 1986;106(1):8-11.

21. Ellman $H$, Hanker G, Bayer M. Repair of the rotator cuff. End-result study of factors influencing reconstruction. J Bone Joint Surg Am. 1986;68(8):1136-44.

22. Rokito AS, Oh YH, Zuckerman JD. Modified Weaver-Dunn procedure for acromioclavicular joint dislocations. Orthopedics. 2004;27(1):21-8.

23. Motamedi AR, Blevins FT, Willis MC, McNally TP, Shahinpoor M. Biomechanics of the coracoclavicular ligament complex and augmentations used in its repair and reconstruction. Am J Sports Med. 2000;28(3):380-4.

24. Lyons FA, Rockwood CA Jr. Migration of pins used in operations on the shoulder. J Bone Joint Surg Am. 1990;72(8):1262-7.

25. Norrell H Jr, Llewellyn RC. Migration of a threaded steinmann pin from an acromioclavicular joint into the spinal canal. A case report. J Bone Joint Surg Am. 1965;47:1024-6.

26. Baker JE, Nicandri GT, Young DC, Owen JR, Wayne JS. A cadaveric study examining acromioclavicular joint congruity after different methods of coracoclavicular loop repair. J Shoulder Elbow Surg. 2003;12(6):595-8.

27. Algarín JR, Salcedo JD, Rodríguez JO, Bello AG, Sancho FB. [Grade III acromioclavicular dislocation treated with a minimally invasive approach]. Acta Ortop Mex. 2010;24(5):317-23.

28. Lädermann A, Grosclaude M, Lübbeke A, Christofilopoulos P, Stern R, Rod T, et al. Acromioclavicular and coracoclavicular cerclage reconstruction for acute acromioclavicular joint dislocations. J Shoulder Elbow Surg. 2011;20(3):401-8. 